\title{
Pembelajaran Fisika Dengan Metode Mindmapping Menggunakan Mindmeister Pada Materi Rangkaian Arus Searah
}

\author{
Dewi Dewantara \\ Pendidikan Fisika FKIP Universitas Lambung Mangkurat \\ Banjarmasin, Indonesia \\ E-mail: dewantarafisika@gmail.com
}

\begin{abstract}
Abstrak
Artikel ini bertujuan untuk mendeskripsikan peningkatan hasil belajar mahasiswa pada materi rangkaian arus searah setelah menerapkan pembelajaran dengan metode mind mapping menggunakan aplikasi mindmeister. Jenis penelitian ini adalah pre-eksperimen dengan metode one group pretest posttest design. Jumlah sampel penelitian adalah 15 orang mahasiswa. Teknik pengumpulan data adalah dengan menggunakan pre-test dan post-test. Data dianalisis dengan menggunakan uji N-Gain dan uji-t berpasangan. Hasil N-gain diperoleh nilai sebesar 0,59 yang berarti peningkatannya berkategori sedang. Hasil analisis uji-t diperoleh nilai $t=-6,650$ dengan sig (2-tailed) $=0,000$ yang lebih kecil dari taraf signifikansi yakni 0,05. Simpulan dari hasil penelitian ini adalah terdapat peningkatan antara pre-test dan post-test mahasiswa pada materi rangkaian arus searah setelah menerapkan Pembelajaran dengan metode mind mapping menggunakan mindmeister.
\end{abstract}

Kata kunci: mind mapping, mindmeister.

\begin{abstract}
This article aims to describe the improvement of student learning outcomes in direct current circuit material after applying learning with mind mapping methods using the mindmeister application. The type of this research is preexperiment with one group pretest posttest design method. The number of research samples was 15 students. The data collection technique used was the pre-test and post-test. Data were analyzed using the N-Gain test and paired $t$-test. The $N$-gain results obtained a value of 0.59 which means that the increase is in the medium category. The results of the $t$-test analysis obtained the value $t=-6,650$ with sig (2-tailed) $=0,000$ which is smaller than the significance level of 0.05 . The conclusion from the results of this study is that there is an increase in student learning outcomes in direct current circuit material after applying Learning with the mind mapping method using mindmeister.
\end{abstract}

Keywords: mind mapping, mindmeister.

\section{PENDAHULUAN}

Fisika adalah ilmu yang mempelajari sifat materi, energi dan gejala yang dialami bendabenda di alam, serta menjadi dasar perkembangan ilmu teknologi dalam kehidupan sehari-hari. Salah satu pokok bahasan dalam fisika di sekolah menengah atas adalah rangkaian arus searah. Guna menyiapkan bekal calon guru fisika, maka mahasiswa mengikuti mata kuliah Telaah Fisika SM III. Adapun capaian pembelajaran mata kuliah Telaah Fisika SM III khususnya pada materi rangkaian arus searah adalah mahasiswa mampu menguasai berbagai kompetensi pembelajaran, strategi pencapaian kompetensi, dan karakteristik materi ajar rangkaian arus searah, serta mampu menjawab/menyelesaikan berbagai pertanyaan dan persoalan yang menyangkut rangkaian arus searah. Dengan demikian, mahasiswa harus mampu menguasai berbagai pengetahuan dan informasi yang berkaitan dengan rangkaian arus searah agar mampu mengajarkannya kelak di sekolah.

Tuntutan agar mahasiswa calon guru fisika harus mampu menguasai berbagai pengetahuan yang berkaitan dengan rangkaian arus searah harus dipenuhi dengan strategi 
pembelajaran yang membantu mahasiswa menyiapkan bekal tersebut. Salah satu strategi pembelajaran yang dapat membantu dalam mengorganisasikan segala informasi yang diterima adalah mind mapping (Putri \& Supardi, 2015). Penggunaan mind mapping dalam pembelajaran menuntut mahasiswa untuk terlibat secara aktif dalam pembelajaran sehingga memudahkan dalam menerima pelajaran (Ulya, Santoso, \& Hamidi, 2015). Mind mapping juga membantu dalam mengatur dan menyimpan sebanyak mungkin informasi yang diinginkan (Mas'adah \& Supriyono, 2014). Bentuk mind mapping yang seperti peta sebuah jalan di kota mempunyai banyak cabang dapat membuat pandangan menyeluruh tentang pokok masalah dalam suatu area yang sangat luas (Putri, Masril, \& Gusnedi, 2017).

Metode pembelajaran mind mapping dapat meningkatkan hasil belajar (Pebriayani, Arsyad, \& Khaeruddin, 2012). Beberapa hasil penelitian menunjukkan bahwa hasil belajar setelah pembelajaran berbantuan mind mapping lebih tinggi dibandingkan pembelajaran yang tidak dibantu mind mapping (Hairani, Dasna, \& Koeshandayanto, 2016). Mind mapping dapat membantu dalam proses pembelajaran dikelas, penggunanya dapat meringkas bahan dan merumuskan masalahmasalah yang akan disajikan (Jariyah \& Harahap, 2018). Mind mapping mampu memfasilitasi pengembangan kemampuan mahasiswa dalam ranah kognitif, afektif, maupun psikomotorik (Resti, 2015).

Membuat mind mapping saat ini tidak terbatas hanya menggambarkan diatas kerja saja. Beberapa pengembang telah mengembangkan fitur pembuat mind mapping secara online. Salah satu mind mapping online yang dapat digunakan adalah MindMeister. MindMeister adalah aplikasi mind mapping yang berbasis web. Mindmeister menyediakan semua fitur dasar untuk membuat dan mengedit mind mapping (Tucker, Armstrong, \& Massad, 2010). Pengguna MindMeister dapat berkolaborasi dalam mengevaluasi secara kritis sumber-sumber untuk validitas informasi mereka (Caverly, 2013).

Penerapan metode mind mapping menggunakan MindMeister diuji pengaruhnya terhadap hasil belajar mahasiswa. Artikel ini bertujuan untuk mendeskripsikan peningkatan hasil belajar mahasiswa sebelum dan setelah menerapkan pembelajaran dengan metode mind mapping menggunakan MindMeister.

\section{METODE}

Jenis penelitian ini adalah preeksperimen dengan metode one group pretest posttest design. Hal ini karena penelitian ini mengambil satu kelas sampel untuk melihat pengambilan data dan menganalisis peningkatan hasil belajar mahasiswa berdasarkan nilai sebelum dan sesudah penerapan pembelajaran. Pada metode ini Sebuah kelompok penelitian dilakukan pre-test $\left(0_{1}\right)$ terlebih dahulu sebelum diberikan perlakuan $(X)$ dan kemudian dilakukan lagi post-test $\left(\mathrm{O}_{2}\right)$.

$\mathrm{O}_{1} \times \mathrm{O}_{2}$

Penelitian dilakukan pada mahasiswa pendidikan Fisika yang menempuh mata kuliah telaah Fisika Sekolah Menengah III pada tahun 2018. Jumlah sampel penelitian adalah 15 orang mahasiswa. Teknik pengumpulan data adalah dengan menggunakan pre-test dan post-test untuk mengetahui hasil belajar mahasiswa sebelum dan sesudah menerapkan Pembelajaran dengan metode mind mapping menggunakan aplikasi mindmeister. Materi dalam penelitian ini di batasi pada materi rangkaian arus searah.

Peningkatan hasil belajar mahasiswa dalam kaitannya dengan efektivitas pembelajaran dengan metode mind mapping menggunakan aplikasi MindMeister dianalisis dengan menggunakan uji N-Gain. Berikut ini adalah persamaan $\mathrm{N}$-Gain beserta kriteria yang digunakan (Hake, 1998).

$\langle g\rangle=\frac{\left(\%\left\langle S_{f}\right\rangle-\%\left\langle S_{i}\right\rangle\right)}{\left(100-\%\left\langle S_{i}\right\rangle\right)}$

Keterangan:

$\left\langle S_{f}\right\rangle=$ rata-rata posttest

$\left\langle S_{i}\right\rangle=$ rata-rata pretest

Tabel 1. Hasil Uji-t berpasangan

\begin{tabular}{lc}
\hline Kriteria & Rentang Nilai \\
\hline Tinggi & $(\langle g\rangle) \geq 0,7$ \\
Sedang & $0,7>(\langle g\rangle) \geq 0,3$ \\
Rendah & $(\langle g\rangle)<0,3$ \\
\hline
\end{tabular}

Data juga dianalisis dengan 
menggunakan uji-t berpasangan yang diawali dengan uji prasyarat yakni uji normalitas dan uji homogenitas. Hipotesis null $\mathrm{H}_{\circ}$ dalam penelitian ini adalah tidak terdapat perbedaan antara hasil belajar awal dan hasil belajar akhir mahasiswa setelah menerapkan pembelajaran dengan metode mind mapping menggunakan aplikasi MindMeister. Hipotesis alternatif $\mathrm{H}_{a}$ dalam penelitian ini adalah terdapat ada atau tidaknya perbedaan antara hasil belajar siswa sebelum dan setelah menerapkan pembelajaran dengan metode mind mapping menggunakan aplikasi MindMeister. Uji-t berpasangan dilakukan dengan bantuan SPSS.

\section{HASIL DAN PEMBAHASAN}

Pembelajaran dengan metode mind mapping menggunakan aplikasi MindMeister di laksanakan pada materi rangkaian arus searah. Penggunaan MindMeister dilengkapi dengan fitur untuk presentasi, sehingga hal ini akan mememudahkan dalam penyampaian materi dalam pembelajaran.

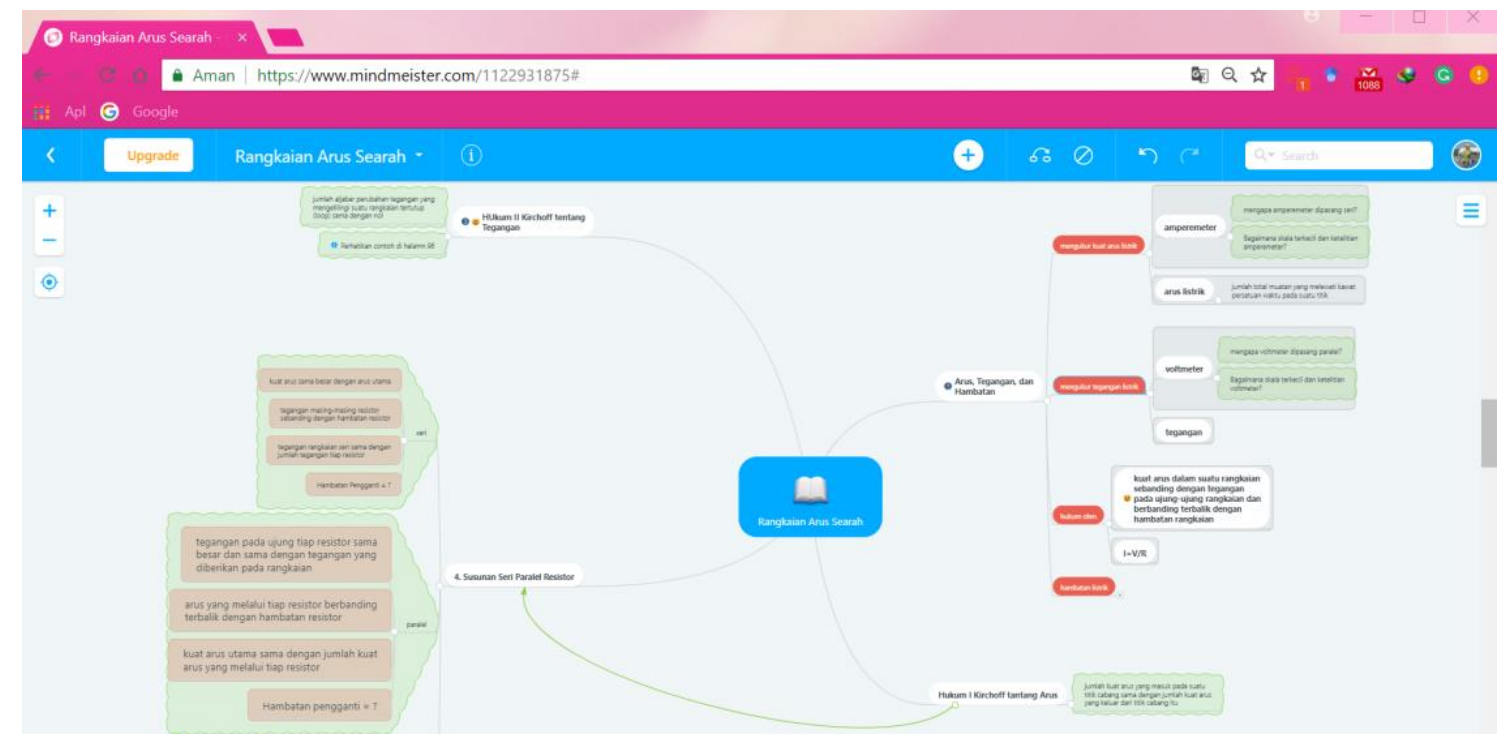

Gambar 1. Tampilan mind mapping pada MindMeister

Hasil uji $\mathrm{N}$-gain memperoleh nilai $\langle g\rangle$ sebesar 0,59. Hasil ini menunjukkan bahwa efektivitas pembelajaran dengan metode mind mapping menggunakan aplikasi MindMeister berkategori sedang.

Tabel 2. Hasil Uji-t berpasangan

\begin{tabular}{cccc}
\hline & $\mathrm{t}$ & $\mathrm{df}$ & Sig. (2-tailed) \\
\hline Pretest - & $-6,650$ & 14 &, 000 \\
Posttest & & & \\
\hline
\end{tabular}

Hasil uji-t berpasangan ditunjukkan pada Tabel 2. Hasil analisis uji-t diperoleh nilai $t=-$ 6,650 dengan sig (2-tailed) $=0,000$ yang lebih kecil dari taraf signifikansi yakni 0,05 . Dengan demikian Hipotesis Nol di tolak, hipotesis alternatif diterima. Hasil analisis paired sample t-test, diperoleh bahwa terdapat perbedaan antara pretest dan posttest mahasiswa pada materi rangkaian arus searah setelah menerapkan pembelajaran dengan metode mind mapping menggunakan aplikasi
MindMeister.

Mind mapping merupakan sistem belajar dan berpikir yang paling banyak digunakan di seluruh dunia (Windura, 2013). Mind mapping menggunakan kemampuan otak akan pengenalan visual untuk mendapatkan hasil yang sebesar-besarnya. Dengan kombinasi warna, gambar, dan cabang-cabang melengkung, mind mapping lebih merangsang secara visual daripada metode pencatatan tradisional, yang cenderung linear dan satu warna. Dengan demikian informasi yang ada pada mind mapping akan lebih mudah diingat (Buzan, 2008). Tampilan warna atau gambar dapat memperlancar pemahaman dan memperkuat ingatan tentang suatu materi (Hasanah, Supeno, \& Wahyuni, 2015). Selain itu, dengan mind mapping proses pembelajaran terasa lebih menyenangkan untuk dilihat, dibaca, dicerna dan diingat (Rianita \& Juliani, 
2017).

Target hasil belajar mahasiswa pada penelitian ini adalah mahasiswa mampu menguasai berbagai kompetensi pembelajaran, strategi pencapaian kompetensi, dan karakteristik materi ajar rangkaian arus searah, serta mampu menjawab/menyelesaikan berbagai pertanyaan dan persoalan yang menyangkut rangkaian arus searah. Mind mapping dapat dijadikan alternatif pada pembelajaran untuk meningkatkan hasil belajar fisika siswa (Choiroh, Ayu, \& Pratiwi, 2018; Pebriayani dkk., 2012). Mind mapping yakni mudah dilakukan, menyenangkan, optimalisasi potensi otak secara keseluruhan serta kesesuaian pembelajaran dengan karakteristik materi fisika (Suwaningsih, Pasaribu, \& Darsikin, 2016). Penggunaan mind mapping mempermudah guru dan siswa, materi yang banyak disampaikan dengan satu tempat sehingga penggunaan waktu lebih efisien (Rianita \& Juliani, 2017).

Mahasiswa yang belajar menggunakan metode pembelajaran mind mapping mempunyai pemahaman yang lebih baik dibandingkan dengan yang menggunakan metode pembelajaran konvensional (Riswanto \& Dasmo, 2015). Mind mapping merupakan cara termudah untuk memasukkan informasi ke dalam otak dan mengingat kembali informasi melalui mencatat kreatif serta mampu mengorganisir informasi yang telah masuk (Choiroh dkk., 2018). Mind mapping merupakan teknik pencatatan yang menghubungkan konsep-konsep berdasarkan kreativitas terhadap suatu konsep dipetakan dalam struktur kognitifnya dan dapat diingat dalam jangka waktu yang lama (Pebriayani dkk., 2012).

\section{PENUTUP}

Simpulan dari hasil penelitian ini adalah terdapat peningkatan antara hasil belajar awal dan hasil belajar akhir mahasiswa setelah menerapkan Pembelajaran dengan metode mind mapping menggunakan aplikasi MindMeister. Berdasarkan hasil penelitian ini disarankan agar dapat mencoba menggunakan metode mind mapping menggunakan aplikasi MindMeister dalam pembelajaran untuk meningkatkan hasil belajar mahasiswa pada materi rangkaian arus searah.

\section{DAFTAR PUSTAKA}

Buzan, T. (2008). Buku Pintar Mind Map. Jakarta: PT Gramedia Pustaka Utama.

Caverly, D. C. (2013). Techtalk: Mobile learning and literacy development. Journal of Developmental Education, 37(1).

Choiroh, A. N. L., Ayu, H. D., \& Pratiwi, H. Y. (2018). Pengaruh model pembelajaran flipped classroom menggunakan metode mind mapping terhadap prestasi dan kemandirian belajar fisika. Jurnal Pendidikan Fisika, 7(1), 1-5.

Hairani, Dasna, I. W., \& Koeshandayanto, S. (2016). Pengaruh model pembelajaran inkuiri terbimbing berbantuan mind mapping terhadap keterampilan proses sains dan prestasi belajar IPA siswa SMP Kelas VII pada pengetahuan awal berbeda. Jurnal Pendidikan Dan Pembelajaran, 23(2), 154-165. http://journal.um.ac.id/index.php/pendidi kan-danpembelajaran/article/view/10166

Hasanah, N. N., Supeno, \& Wahyuni, S. (2015). Kekuatan retensi siswa SMA kelas $X$ dalam pembelajaran fisika pada pokok bahasan momentum dan impuls menggunakan lembar kerja siswa berbasis mind mapping. Jurnal Pembelajaran dan Pendidikan Sains, 2(1), 25-32. https://jurnal.unej.ac.id/index.php/jpps/ar ticle/view/6410

Hake, R. R. (1998). Interactive-engagement versus traditional methods: A sixthousand-student survey of mechanics test data for introductory physics courses. American Journal of Physics, 66(1),

64-74. 
https://doi.org/10.1119/1.18809

Jariyah, A., \& Harahap, M. B. (2018). Pengaruh model pembelajaran problem based learning menggunakan mind map. Jurnal Inovasi Pembelajaran Fisika (INPAFI), 6(1), 1-6. https://doi.org/10.24114/inpafi.v6i1.9400

Mas'adah, \& Supriyono. (2014). Implementasi pendekatan contextual teaching and learning (CTL) dengan teknik mind mapping pada materi elastisitas kelas $X$ SMA Negeri 1 Gedangan. Jurnal Inovasi Pendidikan Fisika (JIPF), 3(2), 149-153. https://jurnalmahasiswa.unesa.ac.id/ind ex.php/inovasi-pendidikanfisika/article/view/8085

Pebriayani, H., Arsyad, M., \& Khaeruddin. (2012). Peningkatan Hasil Belajar Fisika Melalui Metode Pembelajaran Mind Mapping Pada Siswa Kelas VIIIA SMPN 33 Makassar. Jurnal Pendidikan FisikaJournal of Physics Education, 1(2), 169179.

https://journal.unismuh.ac.id/index.php/i pf/article/view/200

Putri, M. P., \& Supardi, Z. A. I. (2015). Penerapan strategi mind mapping pada materi pemanasan global terhadap pemahaman konsep siswa SMA kelas XI. Jurnal Inovasi Pendidikan Fisika (JIPF), $\quad 4(2), \quad$ 129-132. https://jurnalmahasiswa.unesa.ac.id/ind ex.php/inovasi-pendidikanfisika/article/view/12314

Putri, W. R., Masril, \& Gusnedi. (2017). Pengaruh penggunaan LKPD berbasis mind map pada pembelajaran berbasis masalah terhadap pencapaian kompetensi fisika peserta didik kelas XI SMA Negeri 2 Padang pada materi teori kinetik gas dan pemanasan global Mahasiswa. Pillar Of Physics Education, 10 , 169-176. http://ejournal.unp.ac.id/students/index.p hp/pfis/article/view/2573
Resti, V. D. A. (2015). Analisis Kreativitas Mahasiswa Dalam Penyusunan Peta Konsep Berbentuk E-Mind Map Berdasarkan Kajian Neurosains. Jurnal Pendidikan Biologi, 6(2), 128-134. http://journal2.um.ac.id/index.php/jpb/art icle/view/277

Rianita, R., \& Juliani, R. (2017). Penerapan model pembelajaran berbasis masalah berbantuan mind map untuk hasil belajar fisika siswa di SMA Negeri 3 Binjai. Jurnal Inovasi Pembelajaran Fisika, 5(4), 51-56.

https://doi.org/10.24114/inpafi.v5i4.9221

Riswanto, H., \& Dasmo. (2015). Upaya meningkatkan hasil belajar ilmu pengetahuan alam (IPA) dengan metode pembelajaran mind map. Jurnal Formatif, $5(2)$, 100-106. https://journal.Ippmunindra.ac.id/index.p hp/Formatif/article/view/330

Suwaningsih, N., Pasaribu, M., \& Darsikin. (2016). Pengaruh Pembelajaran Kooperatif tipe STAD Berbasis Mind Maping terhadap Hasil Belajar Fisika pada Pokok Bahasan Cahaya di SMP Negeri 18 Palu. Jurnal Pendidikan Fisika Tadulako (JPFT), 5(2), 19-24. http://jurnal.untad.ac.id/jurnal/index.php/ EPFT/article/view/8405

Tucker, J. M., Armstrong, G. R., \& Massad, V. J. (2010). Profiling a Mind Map User: A Descriptive Appraisal. Journal of Instructional Pedagogies, 2.

Ulya, A., Santoso, S., \& Hamidi, N. (2015). Peningkatan hasil belajar melalui penerapan metode peta pikiran pada pembelajaran dasar-dasar perbankan. Jurnal "Tata Arta" UNS, 1(3), 332-342.

Windura, S. (2013). $1^{\text {st }}$ Mind Map Untuk Siswa, Guru, dan Orang Tua. Jakarta: PT Elex Media Komputindo. 